\title{
LASER CHEMISTRY IN FRANCE
}

\section{JACQUES JOUSSOT-DUBIEN}

\section{Université de Bordeaux I}

Laser chemistry began with a good start, in France, when pulsed nanosecond solid state lasers became available to physical and photochemists. Incidently, the first experiment using a $\mathrm{Q}$ switched neodynium laser, revealing excited singlet state spectroscopy, was made at the CGE Company in Marcoussis by Bonneau, Lindqvist and Faure in 1968. Later development followed the general expansion of the field, detecting active species in the chemistry of excited electronic and hot ground states of molecules, tracing radicals, looking for new lasing materials, probing intricate physical phenomena, ablating surfaces etc.

Perhaps the most significant cooperative effort in sharing laser experience in photophysics and photochemistry was made through the initiative of Professor Jean-Claude Lehmann, at the time director of the Physics Department at the CNRS. He launched a research cooperative program called today "Dynamics of Molecular Reactions" patronized by the CNRS to induce physical chemists and chemical physicists to work together. Gas phase and beam chemistry had been slow to develop in France although a scientist like R. Campargue, at the atomic energy center in Saclay, was a pioneer in developing supersonic beams.

The idea was to let small subgroups in different large laboratories keep their activities in their own institutions and at the same time participate to a much larger super group called "Groupement de Recherche" having a central theme of research: elementary processes of chemical reactivity, mainly but not exclusively, in simple systems. This "groupement" extended from the Paris area to Bordeaux, Toulouse and Grenoble.

Presently the Research Group includes more than 80 scientists, active in 17 research operations and having published a little over 200 papers during the 1985-1989 period. A report, in French, is available describing the field covered, the main results and future plans.

The laser certainly revolutionized the approach physical chemists and molecular physicists could make to unravel collisional chemistry, aggregate formation and aggregate reactivity. One can see today how kinetic energy can be transformed into chemical energy at single collision events, how atoms or molecules in different energy state react etc. The irreversibility of primary chemical events seems to be at our fingertip. Of course, all these experimental data are of interest only if confronted to theoretical treatment, and if a coherent scheme can be deducted.

The success of the "Groupement de Recherche", renewed this year by the CNRS, is due to many factors, not the least being the active cooperation of physicists, chemists and theoreticians.

The following two issues of Laser Chemistry gather articles of some French laboratories and research groups in a large "range" of interest in which a laser has brought a decisive impact in the field. 